Anuario de Derecho N ${ }^{\circ}$ 48-2019 - Año XXXIX - ISSN 0553-0814 Edición anual diciembre 2018-noviembre 2019

\title{
EL ESTADO Y EL DERECHO INTERNACIONAL PRIVADO
}

\author{
WILLIAM ESTEBAN GRISALES CARDONA ${ }^{1}$ \\ Corporación Universitaria Americana, Colombia \\ E-mail: estegris@gmail.com \\ DIEGO CORREA C. ${ }^{2}$ \\ Corporación Universitaria Americana, Colombia \\ E-mail: dcorrea@americana.edu.co \\ WALTER MAURICIO MONTAÑN ARIAS \\ Corporación Universitaria Americana, Colombia \\ E-mail: wmontano@americana.edu.co \\ ADRIANA ESTRADA 4 \\ Universidad de Medellín
}

ALEJANDRA ALVAREZ CARMONA

E-mail: alejis210@hotmail.com

\section{RESUMEN.}

La necesidad de generar nuevos espacios es vital en la actualidad, máxime cuando las actividades comerciales de los ciudadanos de diferentes Estados requieren adquirir diversos productos, exigen la creación de normas de carácter internacional que regulen estas actividades, pero que a su vez sean acordes con las normas internas. Las Mipymes se convirtieron en la mejor forma de generar nuevas relaciones comerciales con empresas de igual categoría en otros estados. Tal como se muestra en este artículo, estas empresas han contribuido con el desarrollo de la economía interna y externa de los diferentes países, donde el Derecho Internacional Privado presenta las herramientas más importantes para la evolución comercial, tanto desde los inicios de la humanidad, como con posterioridad a la segunda guerra mundial donde se establece una nueva forma de ver el mundo.

\section{Palabras claves.}

Derecho Internacional Privado. Mipymes, comercio, nuevos espacios.
ABSTRACT.
The need to generate new spaces is vital today, especially when the commercial activities of the citizens of different States require purchasing different products, require the creation of international rules governing such activities, but which are consistent with the internal rules. MSMEs became the best way to generate new business relationships with companies in the same

\footnotetext{
${ }^{1}$ Abogado y Magister en Derecho Procesal de la U. de M., Doctorando en Filosofía de la UPB, Docente tiempo completo de la Corporación Universitaria Americana.wgrisales@coruniamericana.edu.co

${ }^{2}$ Filósofo y Magister en Filosofía de la UPB, Doctorando en Filosofía de la UPB, Docente tiempo completo de la Corporación Universitaria Americana.

${ }^{3}$ Economista, Magister, Doctorando.

${ }^{4}$ Abogada de la U. de M., Maestranda de la Universidad de Medellín, Directora del programa de Derecho

${ }^{5}$ Estudiante de la Facultad de Humanidades y Ciencias Sociales, Programa de Derecho.
} 
category in other States. As shown in this article these companies have contributed to the development of the internal and external economy of different countries. Private international law presents the most important tools for the commercial evolution, from the beginnings of humanity, both after the Second World War to establish a new way of seeing the world.

Keywords. Private International Right. Mipymes, trade, new spaces

Introducción. Este texto surge como resultado inicial de la investigación titulada "El Derecho contractual en el contexto internacional, Mipymes. Una mirada desde la Filosofía Política”, en la cual se muestra la relación entre el Derecho contractual internacional y las Mipymes, lo anterior, tomando como punto de partida la filosofía política. Hoy en día, varios de los conceptos tradicionales de la filosofía política han ido cambiando a lo largo de la evolución histórica del Derecho, de la política y de la misma sociedad, esa evolución se presenta gracias al desarrollo que ha tenido el Derecho internacional privado y la fuerza que este ha tomado en los últimos años, es así como, la relación entre los particulares genera una nueva regulación de las actividades mercantiles desde el punto de vista normativo, comprometiendo al Estado a tener una relación diferente con aquellos que están más allá de sus fronteras territoriales.

Es cierto, las relaciones entre particulares de diferentes Estados se han dado desde tiempo atrás, pero sólo con el auge de las tecnologías de la información y la comunicación TIC, se han hecho mucho más ágiles esas relaciones mercantiles, demandando la presencia de normas mucho más rápidas y adecuadas para resolver los posibles conflictos que se puedan presentar en el desarrollo de los negocios jurídicos. Las normas internacionales de Derecho Privado son hoy en día una necesidad y por ello, es indispensable la ratificación de esos tratados de Derecho privado y la verdadera inclusión en el ordenamiento jurídico interno.

\section{Función del Derecho Internacional Privado y como ha influenciado en la nueva estructura}

del Estado. La influencia mencionada es referente al cambio en el paradigma de la soberanía, entendida como facultad exclusiva dentro de un determinado territorio, ahora tribunales internacionales creados para la solución de casos entre particulares de diferente nación, deben ser reconocidos y también las decisiones que ellos tomen.

En este sentido, importa reconocer que esa necesidad de la legislación internacional (tratados) puede generar contradicción con el manejo que el ordenamiento jurídico interno haga sobre una determinada materia. Además de lo anterior, debe tenerse presente que cada uno de los países poseen sistemas jurídicos diferentes, como, por ejemplo, las relaciones entre particulares de Latinoamérica y anglosajones. Basta con recordar el sistema jurídico vigente, conocido como civil law o sistema continental, mientras que otros países pueden tener un sistema anglosajón o Common law, socialista, entre otros. Dicha diversidad de sistemas contiene, cada uno de ellos, distintas regulaciones en material contractual o de las obligaciones.

De acuerdo con lo anterior, "la función del derecho internacional privado consiste en proporcionar respuestas adecuadas a dichas relaciones, procurando resolver su discontinuidad, al tiempo que 
facilitar las relaciones personales entre los sujetos y los intercambios comerciales a través de las fronteras" (Fernández, 2015, p. 25-26). Con el ejercicio del derecho internacional privado se rompieron las barreras territoriales en cuanto al manejo de las normas jurídicas territoriales.

El derecho internacional privado, tal como sucede con el derecho privado se da una protección especial a la autonomía de la voluntad. Esta comprende la posibilidad de autogobernar las reglas que regirán las respectivas relaciones contractuales entre los particulares. En el artículo 1602 del Código Civil Colombiano, se establece que el contrato es ley para las partes, esto significa que para los nacionales colombianos el acuerdo de voluntades prima sobre la ley, la cual es supletiva. Sin embargo, esta posibilidad de autogobernar la voluntad contractual no es amplia desde las legislaciones internas, por ejemplo, en el caso colombiano los artículos 19 y 21 señalan las reglas que se deben tener en cuenta frente a las distintas relaciones privadas que se generan. Para los casos del estado civil de las personas y asuntos de familia, se aplicarán las normas colombianas independientes del Estado en que se encuentre el nacional colombiano. Para los eventos de actividades negociales se aplicarán las normas del lugar de la celebración del contrato.

Las anteriores normas, en especial la segunda, antes de la aparición del Internet no tenía discusión, pero ahora cuando mediante un click se cierran negociaciones, se debe aclarar ¿Dónde se celebró el contrato? ¿Se rige por las reglas del país del aceptante o las reglas del país del oferente? Ante el incumplimiento ¿qué norma procesal se aplicaría? Son interrogantes a los que se aboca este texto y espera dar una respuesta acorde al nuevo modelo de Estado exigido por esta serie de relaciones contractuales.

El Estado debe crear normas acordes con las exigencias actuales de la comunidad y de manera especial del comercio, reconocer que ya este trascendió sus fronteras no solo a través de las grandes empresas, sino también a través de las denominadas medianas y pequeñas empresas, que son las que mayormente hacen uso de los tratados internacionales.

Estas empresas constituyen más del $90 \%$ del total global, contribuyendo casi al $50 \%$ del PIB mundial y emplean más del $70 \%$ de la fuerza de trabajo. Sin embargo, de acuerdo al informe 2016 de la OMC, participan de manera desigual y con grandes dificultades en el comercio internacional, que es sin duda el ámbito de crecimiento para los países y para ellas mismas. Los datos demuestran que, en el caso de los países desarrollados, constituyen el $78 \%$ de los exportadores, pero sólo el $34 \%$ de las exportaciones. Y en el caso de los países en desarrollo, dan cuenta solamente del $8 \%$ de las exportaciones de manufacturas, que en África llega sólo al 3\%. Si se trata de exportación de servicios, las Mipymes llegan al 1\% de las ventas totales en el mercado formal (Casanueva, 2017).

En el contexto colombiano se encuentra:

No cabe duda sobre la importancia de las Pymes en nuestro país. Las micro, pequeñas y medianas empresas son fundamentales para el sistema productivo 
colombiano, como lo demuestra el hecho de que, según el Registro Único Empresarial y Social (Rues), en el país 94,7\% de las empresas registradas son microempresas y 4,9\% pequeñas y medianas", explica Julián Domínguez, presidente de la Confederación Colombiana de Cámaras de Comercio (Confecámaras)" (Dinero, 2019).

De acuerdo con lo anterior, el papel de las Mipymes en el comercio internacional es de gran importancia, lo que exige que países como Colombia y los de América Latina tengan una relación contractual internacional adecuada, además de ser reconocida en cada ordenamiento jurídico interno. No basta con participar de los diálogos multilaterales para la creación de normas internacionales sobre una materia, se requiere adicionalmente el reconocimiento de estas en un orden jurídico coordinado, ordenado, de una sola reglamentación y no de leyes sueltas en materia internacional.

Adicional a lo anterior, se requiere establecer normas procesales claras para la solución de las eventuales controversias. La legislación procesal colombiana, establece en el artículo 605 el reconocimiento de las sentencias extranjeras de acuerdo a los tratados internacionales suscritos. Lo anterior permite manifestar que "La jurisdicción es, pues, una función de Estado que no queda afectada por la existencia de elementos extranjeros en el proceso” (Fernández, 2015, p. 51)

Las normas internacionales deben estar acordes, tal como se dijo anteriormente, con el ordenamiento jurídico, es decir, entre las normas internas y externas debe existir la menor discrepancia posible. El legislador en su tarea debe generar leyes que permitan el desarrollo de normas internacionales, en este caso, normas que favorezcan la evolución de las Mipymes y de las actividades que ellas realizan.

Los convenios, los contratos, las obligaciones establecidas por los contratantes requieren un alto grado de coercibilidad, es decir, contar con mecanismos fuertes para lograr el cumplimiento forzado de lo pactado. La posibilidad de tener una jurisdicción internacional, obliga a los Estados a abrir sus fronteras y su soberanía, para aceptar o recibir un orden internacional que regule de una $\mathrm{u}$ otra forma las conductas de sus nacionales. Las Mipymes como personas jurídicas tienen su nacionalidad, su domicilio, su país, entre otros.

Dentro de las características de las normas del Derecho Internacional Privado, está la de fijar la competencia para conocer de las distintas controversias que se susciten entre los contratantes, por ello

Las normas de competencia judicial internacional, por su naturaleza, presentan un carácter unilateral, toda vez que únicamente proceden a delimitar el ámbito jurisdiccional de los tribunales de un Estado. En un régimen convencional o institucional, sin embargo, la característica esencial es la bilateralidad de las normas que incorporan. Los textos convencionales proceden a repartir, distribuir o localizar 
la competencia judicial internacional en los distintos Estados parte en dicho régimen (Fernández, 2015, p. 55).

El derecho internacional privado cumple la función de prestar regulación de actos entre particulares de diferentes Estados, que por exigencias de las actuales relaciones contractuales se necesita llevar productos a otros territorios, además de generar servicios de primera y segunda necesidad, entre los diferentes contratantes.

Espacios Geopolíticos. Estos espacios surgen en un primer momento después de la segunda guerra mundial, momento en el cual se hace una reestructuración del mundo en torno a dos naciones, pero también durante ese periodo el comercio empieza a romper las fronteras, y las necesidades poblacionales llevan a que se dé una nueva forma de negociación. Ya los tribunales internacionales no solo se crean para efectos penales, también comienzan el desarrollo de otros tribunales dedicados a resolver controversias en el ámbito comercial.

A pesar de lo anterior, en materia comercial, la necesidad de realizar intercambios de materias primas o de productos es mucho más antiguo, desde los albores de la humanidad se ha necesitado de este intercambio, creándose en cada momento en particular reglas o normas para la regulación de la actividad comercial. Puede decirse que:

En el Renacimiento se empezaron a abrir fronteras geográficas que limitaban el mundo antiguo. El hombre se aventuró allende esos límites, supo que podía vivir en parajes exteriores al espacio hasta entonces familiar. Primera gran apertura del mundo vivido, más allá de la morada ancestral... (Villoro, 2010, p. 142).

El ir más allá de sus fronteras, no solo para buscar una nueva vida, si no también productos con los cuales trabajar, requieren del Estado, la creación de normas que protejan a sus nacionales, pero esas reglas deben ser de carácter universal, internacional, y como se dijo anteriormente, de tribunales que resuelvan los conflictos y las normas a aplicar.

En el caso de los tribunales arbitrales internacionales ha habido una evolución paralela al proceso de mundialización capitalista: concebidos inicialmente para dirimir conflictos bien entre Estados o bien de Derecho Privado nacional e internacional entre particulares, fueron ampliando su jurisdicción a los conflictos entre Estados y particulares. En este último caso, primero, solo se ocuparon de las controversias surgidas en la interpretación y aplicación de contratos y, luego, se extendieron a la responsabilidad extracontractual de Derecho Privado hasta alcanzar la esfera del Derecho Público (Observatorio de multinacionales en América Latina, 2019).

Pero no solo se trata de materia arbitral, también se encuentran cámaras de comercio internacionales, centros de conciliación, entre otros; tribunales que diseñan un marco normativo para la solución de conflictos en materia de comercio internacional. 
Lo anterior, lleva a darse espacios geopolíticos diferentes a los simplemente materiales, tal vez como los establecidos por Rusia y Estados Unidos. Esos espacios a que se hace referencia están mediados las tecnologías de la información y la comunicación. Las negociaciones que se realizan actualmente, como se dijo antes, solo requieren de un click para formar el consentimiento en un negocio jurídico.

Un ejemplo del manejo de información, se encuentra en google maps, allí se puede observar al mundo entero, puede verse el lugar con quien se está negociando, incluso hasta ver el local comercial o el domicilio de la persona, en tanto que "Da la impresión de que hoy cualquier parte de la tierra puede ser potencialmente observada y cartografiada online por cualquiera, sin el inevitable sesgo subjetivo y los prejuicios del cartógrafo" (Brotton, 2014, p. 486). El manejo de la información ha establecido la necesidad de un nuevo espacio para el comercio y las leyes que lo regulen por fuera del espacio territorial del Estado (Soberanía).

Desde el punto de vista económico, los dos modelos más importantes son: el Capitalismo y el socialismo. El primero de ellos, tiene origen en la edad media a partir del fortalecimiento de la riqueza de los Estados, posteriormente y como parte de su desarrollo aparece el expansionismo mercantil, generando la presencia de la empresa privada, ya como productora de bienes y servicios.

Esta teoría económica es hoy por hoy una política económica, y así puede percibirse desde la misma Constitución Política de Colombia, tal como se desprende de su artículo 333:

La actividad económica y la iniciativa privada son libres, dentro de los límites del bien común. Para su ejercicio, nadie podrá exigir permisos previos ni requisitos, sin autorización de la ley. La libre competencia económica es un derecho de todos que supone responsabilidades. La empresa, como base del desarrollo, tiene una función social que implica obligaciones. El Estado fortalecerá las organizaciones solidarias y estimulará el desarrollo empresarial. El Estado, por mandato de la ley, impedirá que se obstruya o se restrinja la libertad económica y evitará o controlará cualquier abuso que personas o empresas hagan de su posición dominante en el mercado nacional. La ley delimitará el alcance de la libertad económica cuando así lo exijan el interés social, el ambiente y el patrimonio cultural de la Nación.

A manera de ejemplo, puede citarse el caso colombiano en lo que se refiere a la vía económica. De esto lo que establece en el artículo señalado, la Corte Constitucional Colombiana ha manifestado en su sentencia C-032 de 2017 lo siguiente:

En materia económica la Carta de 1991 adoptó el modelo de economía social de mercado. En este sentido ha dicho la Corte Constitucional, que el Estado Constitucional colombiano es incompatible tanto con un modelo del liberalismo económico clásico, en el que se proscribe la intervención estatal, como con modalidades de economía de planificación centralizada en las que el Estado es el único agente relevante del mercado y la producción de bienes y servicios es un 
monopolio público. En contrario, la Carta adopta un modelo de economía social de mercado, que reconoce a la empresa y, en general, a la iniciativa privada, la condición de motor de la economía, pero que limita razonable y proporcionalmente la libertad de empresa y la libre competencia económica, con el único propósito de cumplir fines constitucionalmente valiosos, destinados a la protección del interés general. De acuerdo con lo anterior, el texto constitucional fue dispuesto para una sociedad de mercado, es decir, para un tipo de organización que desarrolla procesos ágiles de intercambio, que buscan no sólo la satisfacción de necesidades básicas, sino también la obtención de ganancia, bajo el supuesto según el cual, la actividad económica debe ser dinámica y estar en crecimiento, todo ello en un escenario (el mercado) fundado en la libertad de acción de los individuos (las libertades económicas), en el que las leyes de producción, distribución, intercambio y consumo se sustraen a la reglamentación consiente y planificada de los individuos, cobrando vida propia.

Para finalizar, es necesario decir que no solo los países desarrollados son los que intervienen en el cambio del mundo con sus grandes y medianas empresas, también los países en desarrollo con la promoción de las pequeñas y medianas empresas, las cuales ayudaron a mejorar los ámbitos empresarial, económico y comercial de los distintos países.

Las críticas a la presentación del subdesarrollo como etapas históricas superables pueden realizarse desde distintos frentes. La experiencia histórica nos ha mostrado que no existe un camino único generalizable; ni siquiera podemos insinuar que se trate de un estadio imperfecto, haciendo abstracción del contextos interregional y supranacional. Cabe pensar, no obstante, que si cada parte del sistema sigue la evolución que le corresponde, la distancia entre los países desarrollados y los subdesarrollados no desaparecerá. Lo más próximo a la realidad es que desde las regiones ricas «surgen» actuaciones y se desencadenan mecanismos que, en vez de ayudar frenan y bloquean las posibilidades de desarrollo de los más pobres. Por otra parte, en lo que a los automatismos del crecimiento y la redistribución se refiere, nada mejor que fijarse de nuevo en las experiencias vividas en los últimos años; en los procesos sociales y económicos no parece que existan automatismos correctores de los desequilibrios, muy por el contrario, los desajustes se nos muestran como un fenómeno acumulativo (Sotelo N, 2001).

Los Estados deben buscar nuevos espacios tanto internos como externos, que permitan la evolución y desarrollo de sus empresas, solo de esa forma podrán avanzar y salir del subdesarrollo o de ser países en desarrollo, como el caso de los países latinoamericanos.

Conclusión. Desde el mismo Derecho Romano, como también en otros espacios geográficos de la antigüedad el comercio se convirtió en un elemento social para el avance de las distintas comunidades. Esos intercambios fueron en aumento implicando ya la necesidad de generar normas 
que permitan solucionar las controversias que entre ellos se puedan suscitar. El Derecho Internacional Privado, es decir, los distintos acuerdos entre los Estados que regulan esas actividades donde prima la autonomía de la voluntad, establecen las normas sustanciales y procesales para darle solución. Esos tratados imponen la obligación de hacer que dichas normas internacionales sean reconocidas por los ordenamientos internos, además de obligar a realizar normas coherentes con ese orden externo. Las Mipymes se han convertido en la mejor forma de incentivar el comercio y la economía interna pero vista como una buena oportunidad del intercambio de productos, eso lo muestra la importancia que han cogido estas en los últimos años. Y como consecuencia de lo anterior, el Derecho Internacional Privado ha ido en aumento en las distintas legislaciones latinoamericanas y distintas ratificaciones de tratados que ha hecho Colombia.

\section{Referencias}

Brotton, J. (2014). Historia del mundo en 12 mapas. Bogotá: Debate.

Casanueva, H. (24 de julio de 2017). Las mipymes en el comercio internacional. América Económica.

Dinero. (16 de Febrero de 2019). Mipymes generan alrededor del 67\% del empleo en Colombia. Dinero.

Fernández R, J. C. (2015). Derecho Internacional Privado. Navarra: Civitas.

Observatorio de multinacionales en América Latina. (18 de febrero de 2019). http://omal.info/spip.php?article4809. Recuperado el 18 de Febrero de 2019, de http://omal.info/spip.php?article4809: http://omal.info/spip.php?article4809

Sotelo N, J. A. (2001). Modelos territoriales vs modelos de desarrollo en el nuevo mapa geopolítico mundial. Anales de geografía de la Universidad Complutense, 311-341.

Villoro, L. (2010). El pensamiento moderno. Filosofía del Renacimiento. México: Fondo de Cultura Económica.

Artículo recibido: 11 de diciembre de 2018

Aprobado: 20 de diciembre de 2018 
